\title{
Live and trending: the next step for public health campaigns?
}

\section{Dheepa Jeyapalana,b, Amy Jo Vassallo and Becky Freemana}

a Prevention Research Collaboration, School of Public Health, University of Sydney, NSW, Australia

b Corresponding author: dheepa.jeyapalan@sydney.edu.au

\section{Article history}

Publication date: December 2017

Citation: Jeyapalan D, Vassallo AJ,

Freeman B. Live and trending: the next step for public health campaigns? Public Health Res Pract. 2017;27(5):e2751741. https://doi. org/10.17061/phrp2751741

\section{Key points}

- Food and beverage manufacturers are using new social media platforms to market their products to children, adolescents and young adults in real time

- The reach of social media is immense, and there are currently little to no regulations to limit unhealthy advertising on these platforms

- Public health and policy responses to the advertising of unhealthy food and drinks need to embrace these technologies and dedicate resources to deliver effective counter-marketing campaigns

\section{Abstract}

Marketing strategies used by large corporations are rapidly evolving, through the development of novel technologies and multiple marketing channels favoured by young consumers. Formerly small-scale marketing approaches, such as providing free samples at local events, may now have a global reach when paired with live streaming on popular social media sites. The regulation of these live streaming platforms is hugely challenging and likely to remain so in the foreseeable future. To ensure that 'unhealthy' messages are not the only content seen by social media users, public health campaigns should invest in similar technologies in disseminating health promoting messages.

\section{Introduction}

The landscape of advertising has changed drastically over the past 10 years, from traditional billboards, television and radio advertising, where one-way communication flowed from corporations to consumers, to novel social media platforms where consumers are engaging with brands, often with little incentive or reward. ${ }^{1,2}$ One of the latest additions to this ever-evolving space of social media advertising is the immersive technology of live streaming. Individuals and companies can post videos in real time to social media sites to promote interaction with 'followers' and 'friends'. Facebook launched a streaming service in early 2016, encouraging users to engage live with companies by posting emotional reactions to broadcast videos as they watched. ${ }^{3}$ Of concern to public health, the manufacturers of energy-dense, nutrition-poor (EDNP) food and beverages are also adopting this form of advertising to market their discretionary products to consumers in real time.

In June 2017, Coca-Cola Australia discontinued its sugar-free beverage, Coke Zero, to launch a new beverage, Coke No Sugar, stating that it tasted 'closest to the real thing'. ${ }^{4}$ This product was introduced to the Australian market with a live Facebook stream, featuring a group of Australian internet celebrities interacting with viewers while driving around Sydney (Figure 1). ${ }^{5}$ The launch of this product comes amid increasing public pressure to implement a sugar tax and the adoption of policies banning the sale of sugarsweetened beverages (SSBs) for healthcare facilities ${ }^{6}$, which has the potential to reduce company revenue. This promotion provides the opportunity to 
Figure 1. Screen capture of Coca-Cola Australia Live stream $^{5}$

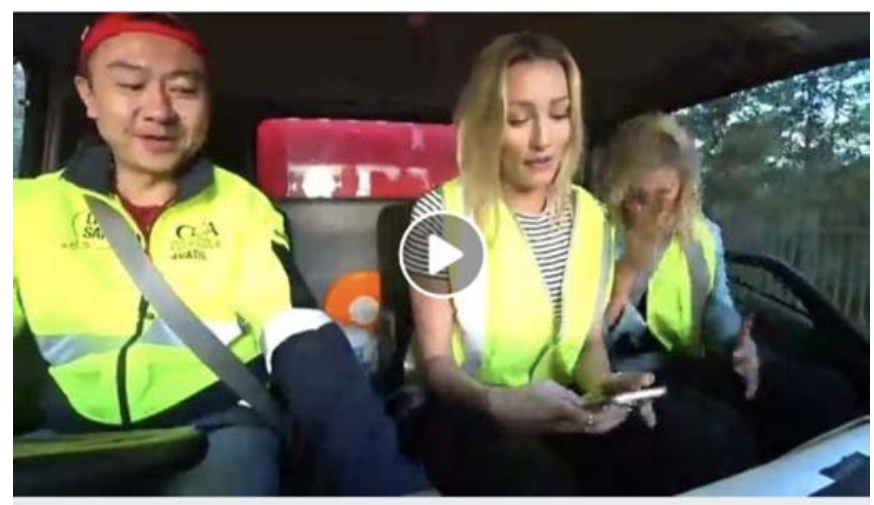

Coce Coca-Cola Australia

15 tupe $\cdot 3$

See what Lana and Madison from SketchShe, Tom Jay Williams, and ChampChong got up to on our LIVE road trip, on our way to deliver the first bottles of Coke No Sugar! (Feat. an acoustic set, truth or dare...and goat-spotting e)

$181 \mathrm{k}$ Views

158 Likes 34 Comments 3 Shares

$\rightarrow$ Share

examine the latest marketing ventures of big food and beverage companies as a case study for health professionals.

The video ended with the group arriving at a central location to provide free samples of the first batch of Coke No Sugar alongside a musical performance by international celebrity Kelly Rowland. Rowland's appearance was not advertised in advance ${ }^{7}$, but rather a surprise for attendees at the time. Therefore, while this generated excitement in the moment, her appearance was unlikely to be the initial drawcard or motivator for audience engagement with this campaign. Despite having initial technical difficulties, hundreds of people tuned into the live stream, and, a week later, more than 180000 people had viewed the video recording on Facebook.

The primary intention behind Coca-Cola's campaign was to establish brand loyalty, 'buzz' and conversation', rather than harm minimisation through the promotion of healthier product alternatives to Coke. We have focused on this campaign because it is the most recent and local example, and similar real-time social media-based marketing strategies have been used for other branded beverages and SSBs. ${ }^{8}$ Although Coke No Sugar may be a zero-calorie alternative to SSBs, there is a lack of evidence to support the role of such drinks to prevent weight gain, as well as a lack of studies on other longterm effects on health. ${ }^{9}$ Importantly, campaigns such as this contribute to the omnipresent marketing of EDNP brands and discretionary products and their presentation as a normal component of a regular diet.
Figure 2. Example of cross promotion of Facebook Live event on Coca-Cola Australia's Instagram page ${ }^{10}$

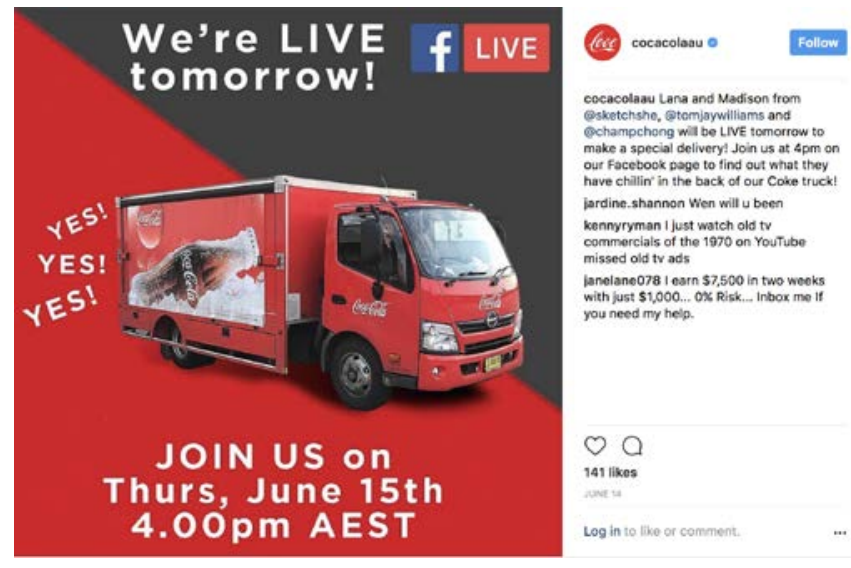

\section{Discussion}

The live stream was heavily promoted in the days before the event on Coca-Cola Australia's Facebook, Instagram and Twitter feeds (Figure 2), as well as the social networks of others.

There was cross-referencing between the three social media platform feeds to encourage consumers to 'like' or 'follow' to ensure they did not miss any updates about this 'live special event'. The Coke No Sugar marketing and publicity event was highly coordinated and strategic. Combining the provision of free samples with this live stream took what traditionally would have been a lowexposure, local marketing tactic to a wide-reaching and global-scale promotion, including attracting online news coverage. Interacting in real time, by asking viewers to comment and include the location where they were watching the video and then replying to these posts, creates additional consumer engagement that is not possible in other advertising channels. These unique, friend-like and emotional responses to Facebook advertising leads to brand familiarity and preference. ${ }^{11}$ This extends the reach of advertising to establishing long-term brand loyalty and consumption of discretionary foods and beverages.

Regulation of social media content is limited at best, with viewers having the ability to flag posts as inappropriate or offensive for review by moderators. Under Facebook's Community Standards, these moderators will remove posts if they depict "nudity, hate speech or violent and graphic content". ${ }^{12}$ However, the real-time nature of live streaming means complaints cannot be acted on until well after an event is over and the harmful exposure has already occurred. Facebook highlights the 'live and unfiltered' appeal of its live streaming function, despite concerns from advocacy groups about the reach of potentially violent, illegal or distressing content. ${ }^{13}$ Although Facebook has recently employed additional moderators to address this issue, the focus will be on preventing the streaming of violence and criminal activity, not on chronic disease prevention. ${ }^{14}$ 
The heavy promotion of Facebook Live, and the funds offered to corporations that use it, mean that this feature is likely to be frequently used in the future as an engaging and wide-reaching marketing strategy. Therefore, public health campaigns should also focus on embracing these technologies to effectively counter the harmful marketing practices of companies selling EDNP foods and beverages. Public health agencies have been somewhat slow to adopt social media use in their social marketing campaigns. There is an urgent need to adopt a more innovative and considered approach to social media-based communications. It is not adequate for public health groups to open a Facebook page and make the occasional post when companies are using real-time promotions with face-to-face events in highly coordinated campaigns. This does have financial implications, and public health organisations do not have the resources to compete with large businesses and their vast marketing budgets. However, as Rowland's musical performance was not previously advertised to the public ${ }^{7}$, an expensive celebrity guest may not necessarily be required for successful public engagement. Rather, the real-time conversation and interaction is what audiences may find so satisfying.

Establishing dedicated social media marketing jobs within public health organisations is potentially a cost-effective response and reasonable allocation of public health resources. Besides Facebook Live feeds, there are additional innovative real-time social media avenues requiring human resources that public health campaigns can use to effectively disseminate public health messages to a large and engaged audience, such as Instagram stories, Periscope or Snapchat. Social media marketing staff members can dedicate the time and strategic thinking required to develop and implement successful social counter-marketing for health promotion ${ }^{15}$ to operate in a space that is currently saturated by companies advertising processed and discretionary food and beverages.

\section{Conclusion}

Much of the current focus of research and policy responses relating to discretionary food and beverage advertising remains on television and print media. With more engaging and interactive forms of advertising emerging through social media, this focus is unlikely to address the types of marketing that children, adolescents and young adults are most likely to view and respond to. ${ }^{16}$ As real-time advertising opportunities become increasingly engaging and difficult to regulate, the public health sector needs to use, and trial dedicating resources to, these same platforms to launch effective social counter-marketing campaigns. ${ }^{15}$

\section{Competing interests}

BF has received money from the World Health Organization, the Sax Institute, Cancer Council NSW, NSW Health, the Union for International Cancer Control, and the Asian Center for WTO \& International Health Law and Policy, National Taiwan University, College of Law.

\section{Author contributions}

$\mathrm{DJ}$ and $\mathrm{AV}$ were equal first authors and responsible for the design, drafting and editing of the manuscript. BF provided specialist advice, and reviewed and edited the manuscript. AV made additional edits based on the reviewer feedback, and all co-authors commented on the edits and approved the final manuscript.

\section{References}

1. Freeman B, Kelly B, Baur L, Chapman K, Chapman S, Gill T, et al. Digital junk: food and beverage marketing on Facebook. Am J Public Health. 2014;104(12):e56-64.

2. Montgomery KC, Grier SA, Chester J, Dorfman L. The digital food marketing landscape: challenges for researchers. In: Williams JD, Pasch KE, Collins CA, editors. Advances in communication research to reduce childhood obesity. New York, NY: Springer New York; 2013. p. 221-42.

3. Simo F. Introducing new ways to create, share and discover live videos on Facebook. Newsroom Fb; 2016 [cited 2017Jun 26]. Available from: newsroom.fb.com/ news/2016/04/introducing-new-ways-to-create-shareand-discover-live-video-on-facebook/

4. Coca-Cola. Atlanta, GA: The Coca Cola Company; 2017 New Coke No Sugar FAQs; 2017 [cited 2017 Jun 26]; [about 4 screens]. Available from: www.coca-cola.com. au/en/new-coke-no-sugar-faqs/

5. Coca-Cola Australia. See what Lana and Madison from SketchShe, Tom Jay Williams, and ChampChong got up to on our LIVE road trip, on our way to deliver the first bottles of Coke No Sugar! (Feat. an acoustic set, truth or dare...and goat-spotting; 2017 [cited 2017 Jun 27]. Available from: www.facebook.com/CocaColaAustralia/ videos/10158812854215153/

6. Hawke S. Sugary drinks being phased out of NSW health facilities in bid to curb obesity rates. ABC News; 2017 [cited 2017 Jul 12]. Available from: www.abc.net.au/ news/2017-06-08/sugary-drinks-to-be-phased-out-of-nswhealth-facilities/8599820

7. Journey Australia Staff. The secrets behind our biggest ever sampling campaign. Coca-Cola Journey; 2017 [cited 2017 Nov 6]. Available from: www.cocacolajourney.com.au/stories/coca-cola-no-sugar-freesamples 
8. Australia C-C. Step back in time with Facebook Live series from the Coca-Cola archives; 2017 [cited 2017 Nov 6]. Available from: www.coca-colacompany. com/coca-cola-unbottled/step-back-in-time-withfacebook-live-series-from-the-coca-cola-a

9. Borges MC, Louzada ML, de Sá TH, Laverty AA, Parra DC, Garzillo JM, et al. Artificially sweetened beverages and the response to the global obesity crisis. PLoS Med. 2017;14(1):e1002195.

10. Coca-Cola Australia. Lana and Madison from @ sketchshe, @tomjaywilliams and @champchong will be LIVE tomorrow to make a special delivery! Join us at 4pm on our Facebook page to find out what they have chillin' in the back of our Coke truck! 2017 [cited 2017 Jul 7]. Available from: www.instagram.com/p/BVTOBucFjAt/

11. Smith S. Conceptualising and evaluating experiences with brands on Facebook. International Journal of Market Research. 2013;55(3):357-74.

12. Facebook. Menlo Park: Facebook; 2017. Community Standards; 2017 [cited 2017 Jul 7]; [about 4 screens]. Available from: www.facebook.com/communitystandards/
13. Sturmer J. Facebook should hide suicide live stream videos, mental health advocates say. ABC News 2017 [cited 2017 Jun 29]. Available from: www.abc.net.au/ news/2017-05-22/facebook-should-hide-suicide-livestreams-from-public-eye/8548126

14. ABC News. Facebook hires thousands of monitors to stop murderers streaming killings online. ABC News; 2017 [cited 2017 Jun 30]. Available from: www.abc.net.au/ news/2017-05-04/facebook-hires-3000-monitors-to-fixstreaming-violence-problem/8495484

15. Bellew W, Bauman A, Freeman B, Kite J. Social countermarketing: brave new world, brave new map. Journal of Social Marketing. 2017;7(2):205-22.

16. Freeman B. Digital junk: food and beverage marketing on Facebook. The Conversation; 2014 [cited 2017 Jun 29]. Available from: www.theconversation.com/digital-junkfood-and-beverage-marketing-on-facebook-32609

\section{Copyright: (c) (i) (2)}

(C) 2017 Jeyapalan et al. This article is licensed under the Creative Commons Attribution-NonCommercial-ShareAlike 4.0 International Licence, which allows others to redistribute, adapt and share this work non-commercially provided they attribute the work and any adapted version of it is distributed under the same Creative Commons licence terms. See: www.creativecommons.org/licenses/by-nc-sa/4.0/ 